\title{
Shear Strength between Ultra-High Performance Concrete and Old Concrete
}

\author{
Hassan Fardoun ${ }^{1}$ and David Begg ${ }^{2}$ \\ ${ }^{1}$ University of Portsmouth \\ ${ }^{2}$ Department of Civil Engineering and Surveying \\ UK
}

\begin{abstract}
This study aims to assess the bond strength and failure mode between old concrete and new concrete through slant shear test. Three different specimens' geometries were considered. Two repairing materials were adopted. The first one is ultra-high performance concrete with reasonable amount of silica fume and the second is high performance concrete with low amount of silica fume. The influence of height on slant shear specimens was studied. Besides the experimental investigation, a numerical analysis using the finite element analysis software LUSAS was conducted and the distribution of shear stresses at the interface were reported. The study presented in this paper reveals that silica fume strengthens the bond in shear. Moreover, it can be stated that height has a significant influence on slant shear specimens and it should be taken into consideration.
\end{abstract}

\section{Introduction and Background}

As concrete structures are coming of age and/or getting exposed to severe environmental and mechanical loading, they tend to deteriorate. Repair stays the preferred option. In repairing process, the bond between old and new concrete has always been a field of interest for its important factor. The strength of this bond is influenced by several parameters (e.g. curing, pozzolanic materials,..). Slant shear test is the most common used technique to study the bond. It is a worldwide technique considered by the American Standard C882 [1] and the British Standard BS EN 12615 [2]. Upon testing, failure can occur in the material itself (cohesive failure) rather than the interface (adhesive failure). Many researchers analysed the failure mode and proposed modifications to enforce adhesive failure [3].

Several repairing materials have been tested. Recently, self-compacting concrete is being proposed as an overlay by some researchers [4]. There is a lack of information of ultra-high performance concrete (UHPC) as a new overlay concrete. UHPC is defined as a cementitious material that its compressive strength exceeds 150 $\mathrm{MPa}$. Silica fume is a major constituent of UHPC required to achieve high strength. It is a material with improved and greater properties that reflect enhanced durability. In line with sustainability, the proposed material would be ideal as it requires less intrusion during its service life. Hence, extending the service life of concrete structures and reducing costs and therefore being the key to the worldwide issue.

This research comprises the use of different types of high performance concrete as an overlay: the first type is ultra-high performance concrete with compressive strength of $160 \mathrm{MPa}$ and reasonable amount of silica fume and the other type is high performance concrete with compressive strength of $120 \mathrm{MPa}$ and very low amount of silica fume. It is aimed to examine the bond strength and failure mode between old concrete and the two different aforementioned repairing materials through slant shear test. Moreover, the study purposes to assess the influence of height on slant shear specimens. Finally, based on the outcome, the research will answer two questions:

- Is the bond strength obtained from specimens with different geometries comparable?

- Would the failure mode be the same, though different geometries are considered? 


\section{Methodology}

\subsection{Experimental Study}

Before any adjustments to height, all specimens were performed according to the British Standard BS EN 12615-1999. Figure 1 below shows the geometry, dimensions and the angle of friction of the specimen.

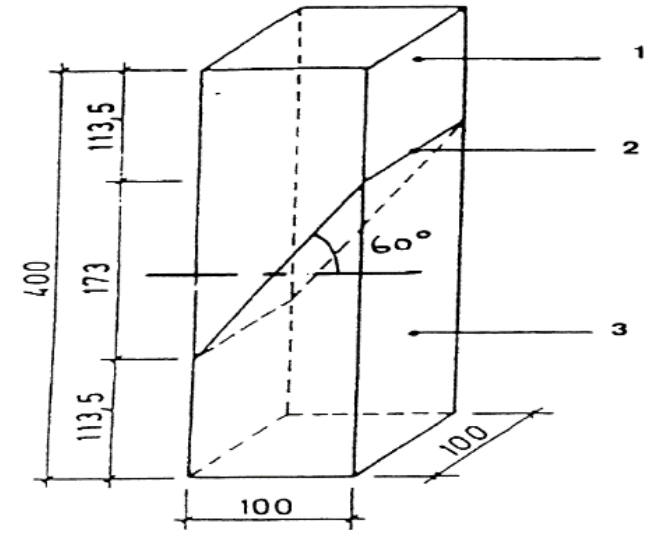

1. Overlay

2. Interface

3. Old Concrete

Fig. 1: Specimen geometry

\subsubsection{Specimen Preparation}

Three prisms were casted in moulds to get the required shape. Figure 2 below shows the casted substrate prisms.

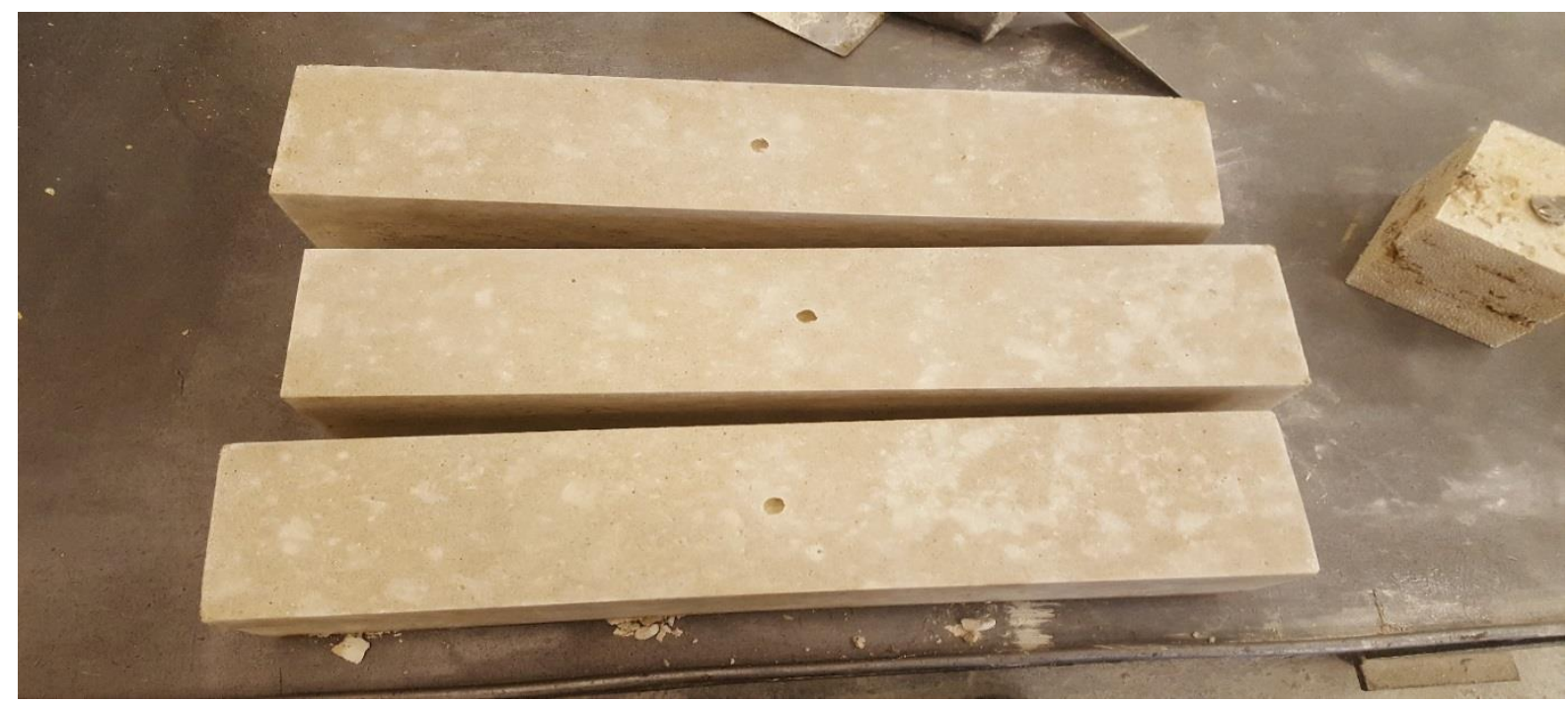

Fig. 2: Substrate prisms.

The mix design adopted for the substrate layers is presented in table 1 below. The compressive strength recorded $75 \mathrm{MPa}$ at 28-days

TABLE 1: Mix Design of the Substrate.

\begin{tabular}{|l|l|l|l|}
\hline Cement $\left(\mathbf{k g} / \mathbf{m}^{\mathbf{3}}\right)$ & Fine Aggregate $\mathbf{( k g / \mathbf { m } ^ { 3 } )}$ & $\begin{array}{l}\text { Coarse Aggregate } \\
\left(\mathbf{k g} / \mathbf{m}^{\mathbf{3}}\right)\end{array}$ & Water $\left(\mathbf{k g} / \mathbf{m}^{\mathbf{3}}\right)$ \\
\hline 410 & 518 & 1208 & 164 \\
\hline
\end{tabular}




\subsubsection{Bonding}

The specimens were saw-cut into halves with a diagonal angle of $30^{\circ}$ with the vertical axis as presented in figure 1. Hand brush was used to clean the surface of old concrete where the present laitance decreases the bond strength. Three overlays out of six were adopted ultra-high performance concrete (UHPC). Silica fume accounted for $11.06 \%$ of cement weight. The compressive strength at 28 -days recorded $150 \mathrm{MPa}$. The mix design considered is presented in table 2 .

TABLE 2: Mix Design of UHPC.

\begin{tabular}{|l|l|l|l|l|}
\hline Cement $\left(\mathbf{k g} / \mathbf{m}^{\mathbf{3}}\right)$ & $\begin{array}{l}\text { Silica Fume } \\
\left(\mathbf{k g} / \mathbf{m}^{\mathbf{3}}\right)\end{array}$ & Silica Sand $\left(\mathbf{k g} / \mathbf{m}^{\mathbf{3}}\right)$ & $\begin{array}{l}\text { Superplasticizer } \\
\left(\mathbf{k g} / \mathbf{m}^{\mathbf{3}}\right)\end{array}$ & Water $\mathbf{( k g / \mathbf { m } ^ { \mathbf { 3 } } )}$ \\
\hline 1075 & 119 & 1050 & 40 & 173 \\
\hline
\end{tabular}

The other three overlays concrete were considered high performance concrete (HPC). The mix design was adopted based on the UHPC mix (table 2). The $119 \mathrm{~kg} / \mathrm{m} 3$ of silica fume considered in the UHPC mix was reduced to $30 \mathrm{~kg} / \mathrm{m} 3$ in the HPC. The amount of silica fume removed $(89 \mathrm{~kg} / \mathrm{m} 3)$ was added to the amount of cement in the HPC mix to become $1164 \mathrm{~kg} / \mathrm{m} 3$. To maintain a constant w/c, water was added. The addition of more dosages of superplasticizer was adopted as the mix seemed to need more water. The compressive strength at 28-days recorded $120 \mathrm{MPa}$. The mix design is displayed in table 3 below.

TABLE 3: Mix Design of HPC.

\begin{tabular}{|l|l|l|l|l|}
\hline Cement $\left(\mathbf{k g} / \mathbf{m}^{\mathbf{3}}\right)$ & Silica Fume $\left(\mathbf{k g} / \mathbf{m}^{\mathbf{3}}\right)$ & Silica Sand $\left(\mathrm{kg} / \mathbf{m}^{\mathbf{3}}\right)$ & $\begin{array}{l}\text { Superplasticizer } \\
\left(\mathbf{k g} / \mathbf{m}^{\mathbf{3}}\right)\end{array}$ & Water $\left(\mathbf{k g} / \mathbf{m}^{\mathbf{3}}\right)$ \\
\hline 1164 & 30 & 1050 & 65 & 195 \\
\hline
\end{tabular}

Figure 3 below clarifies the prepared specimens before any height adjustments. Figure 4 shows a slant shear specimen.

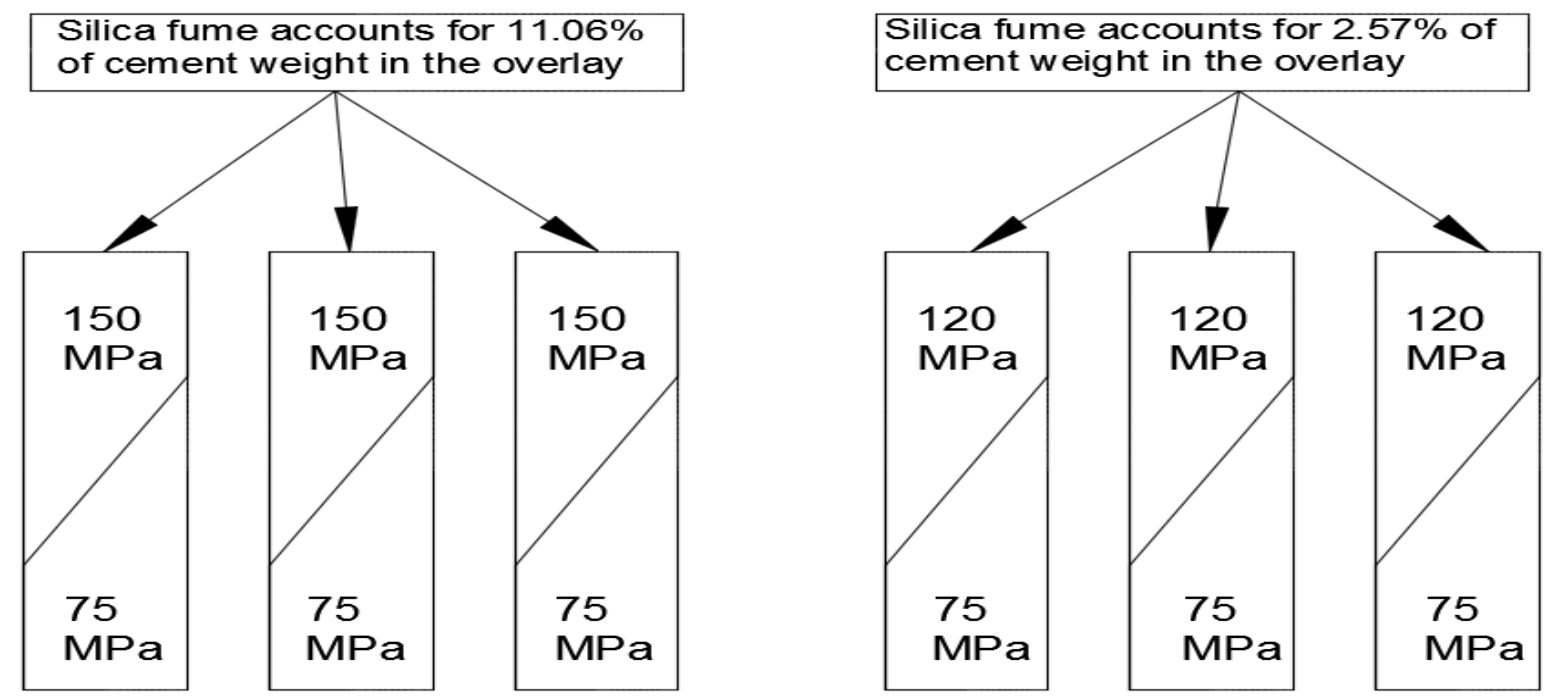

Fig. 3: Specimens before height adjustments. 


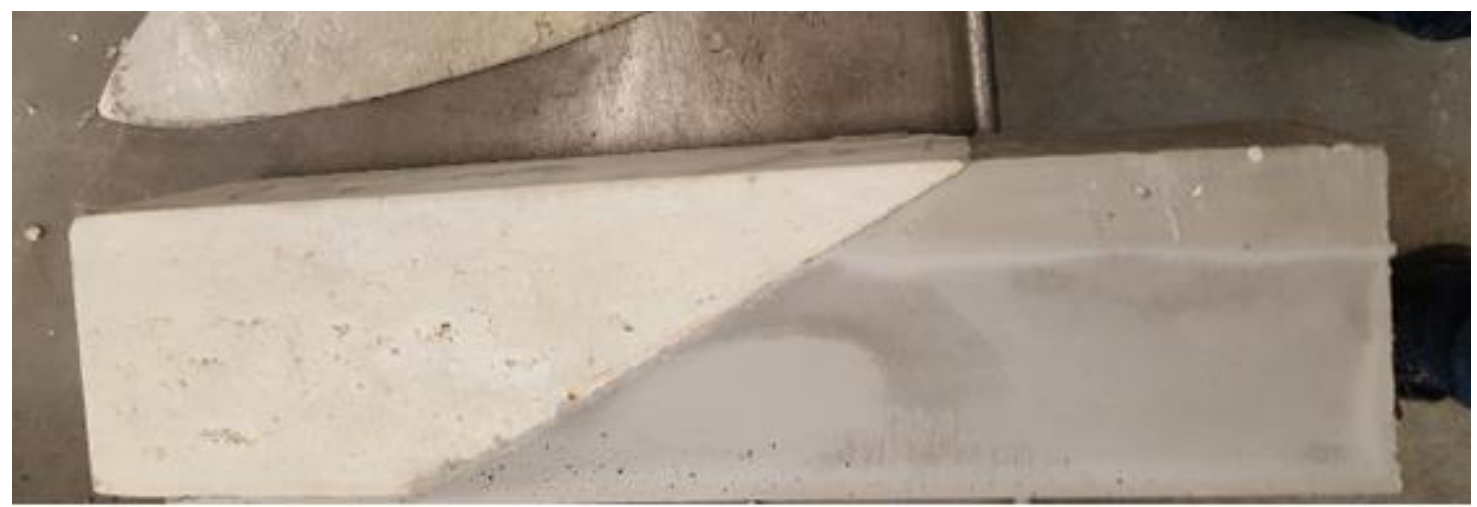

Fig. 4: A slant shear specimen.

\subsubsection{Adjustments to Geometry}

Set 1: No adjustments. Two specimens were involved:

- A 400-mm specimen having ultra-high performance concrete as an overlay (150 MPa of compressive strength and silica fume accounts to $11.06 \%$ of cement weight).

- A 400-mm specimen possessing high performance concrete as an overlay (120 MPa of compressive strength and silica fume accounts to $2.57 \%$ of cement weight).

Set 2: Adjustments in both halves. The smaller part was adopted $20 \mathrm{~mm}$. Figure 5 below clarifies this. The specimens chosen were the same as in set 1 .
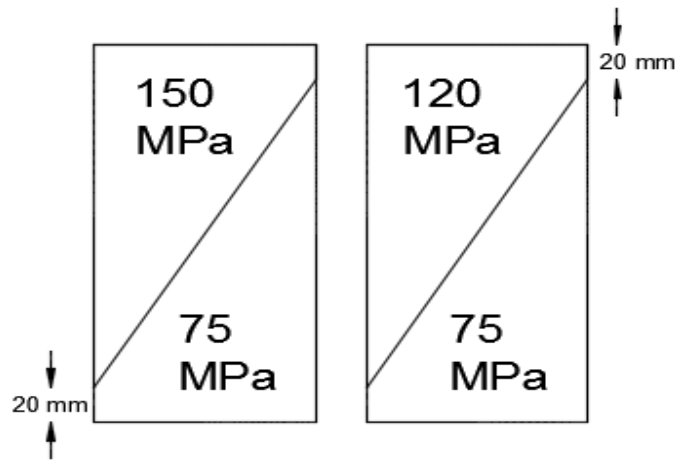

Fig. 5: Adjustments in both halves.

Set 3: The smaller height of the overlay half was kept as it is at $113.5 \mathrm{~mm}$ as specified in EN 12615-1999 while the smaller side of the substrate was reduced to $45 \mathrm{~mm}$. The remaining two specimens, the same as in the previous sets, were involved.

\subsection{Numerical Analysis}

A numerical study was conducted using the finite element analysis software LUSAS. The simulation comprised the following:

Set A: A simulation to study the influence of differential stiffness was carried out first. Simulation for three models took place with dimensions as in set 1 . The compressive strength of the substrate was common in all specimens with a value of $25 \mathrm{MPa}$. Regarding overlays, the compressive strengths adopted were $25 \mathrm{MPa}, 75$ $\mathrm{MPa}$ and $105 \mathrm{MPa}(25 / 25,25 / 75,25 / 105)$.

Set B: A simulation to study the effect of reducing the base height to $20 \mathrm{~mm}$ as in set 2 of the experiment was conducted. A 35/37 specimen was considered.

Set C: A simulation to study the effect of reducing the base height in the substrate only was carried out. As in set 3 of the experiment, the smaller side of the substrate half was reduced to $45 \mathrm{~mm}$ while it was kept at 113.5 $\mathrm{mm}$ for the overlay half. A 75/105 specimen was considered. Figure 6 clarifies this. 


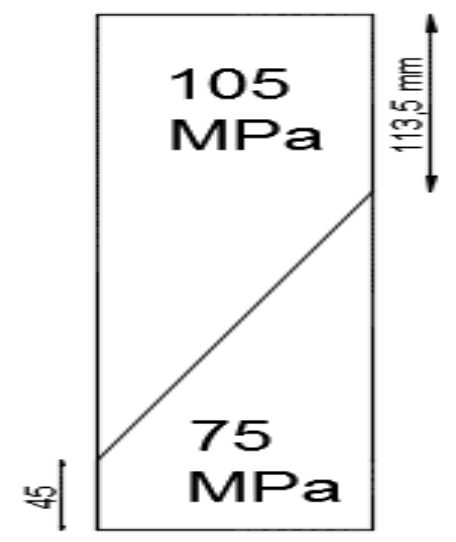

Fig. 6: Adjustments in the substrate base half.

\section{Results and Discussion}

\subsection{Set 1 and Set $A$}

Due to physical restrictions, the load applied on the specimens could only reach $250 \mathrm{KN}$. The UHPCspecimen stayed still and therefore the bond strength was not determined. The HPC-specimen reported failure at $230 \mathrm{KN}$ and therefore the slant shear strength is: $\mathrm{Fb}=\mathrm{F} \sqrt{3} / 40000=230000 * \sqrt{3} / 40000=9.95 \mathrm{MPa}$. A higher bond strength was reported in the UHPC specimen as no failure occurred. Diab in his experiment concluded that the maximum effect of the overlay compressive strength to the old concrete compressive strength ratio on bond strength is when it reaches 1.4 and any increase beyond $40 \%$ has a slight and modest improvement [4]. In this study, the aforementioned ratio exceeds the threshold in all sets and hence it has no significant impact. Therefore, the higher bond strength recorded in the UHPC-specimen may be attributed to the higher amount of silica fume presented in its overlay (11.06 \% of cement weight). This agrees with Wan's study [5] and contradicts Mohammadi's research [6].

Regarding the failure mode, a cohesive failure was reported. The simulation took place to the models in set A shows approximately a uniform distribution of shear stresses at the interface for the specimen with same compressive strength in both halves (figure 7 -a), however, as the differential stiffness increases, the difference in stresses increases. Figure 7 -c shows a significant change which represent the 25/105 specimen. Figure 8 represents the values. The cohesive failure stated may be attributed to the high differential stiffness between the two halves of the specimen.

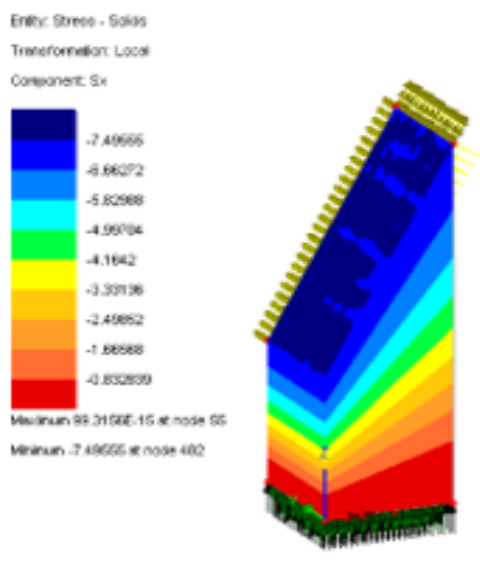

(a)

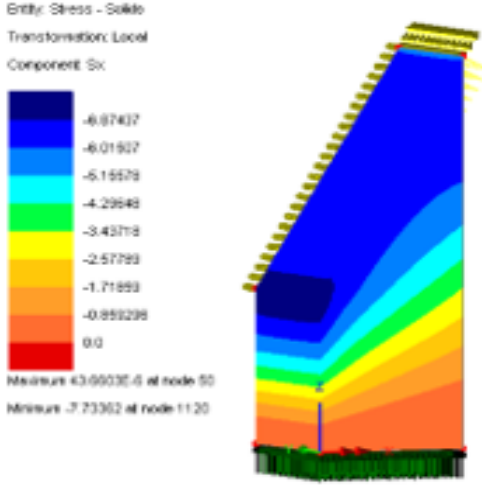

(b)

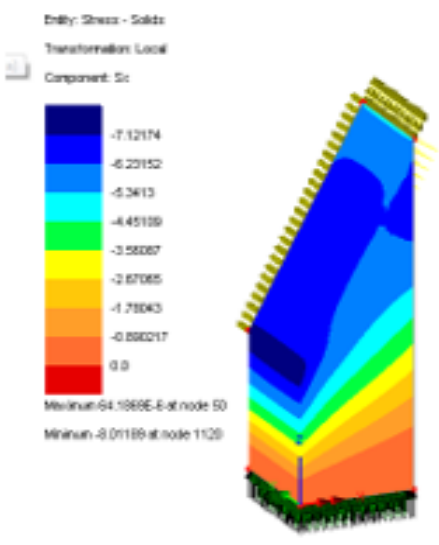

(c)

Fig. 7: The influence of differential stiffness on the distribution of shear stresses. 


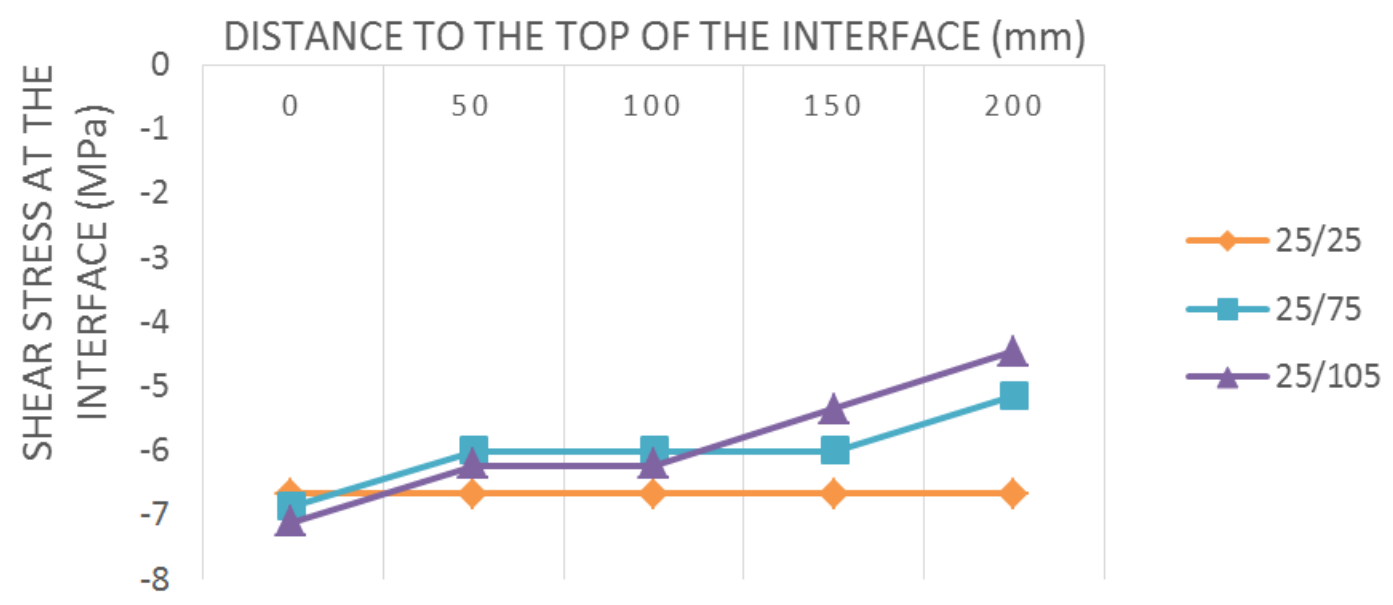

Fig. 8: Distribution of shear stresses at the interface.

\subsection{Set 2 and Set $B$}

Regarding the bond strength, 3.87 MPa and 2.91 MPa was reported for the UHPC and HPC specimens, respectively. The higher bond strength may be attributed to the same reason mentioned for set 1 .

Regarding the failure mode, adhesive failure was noticed in both specimens as shown in figure 9.
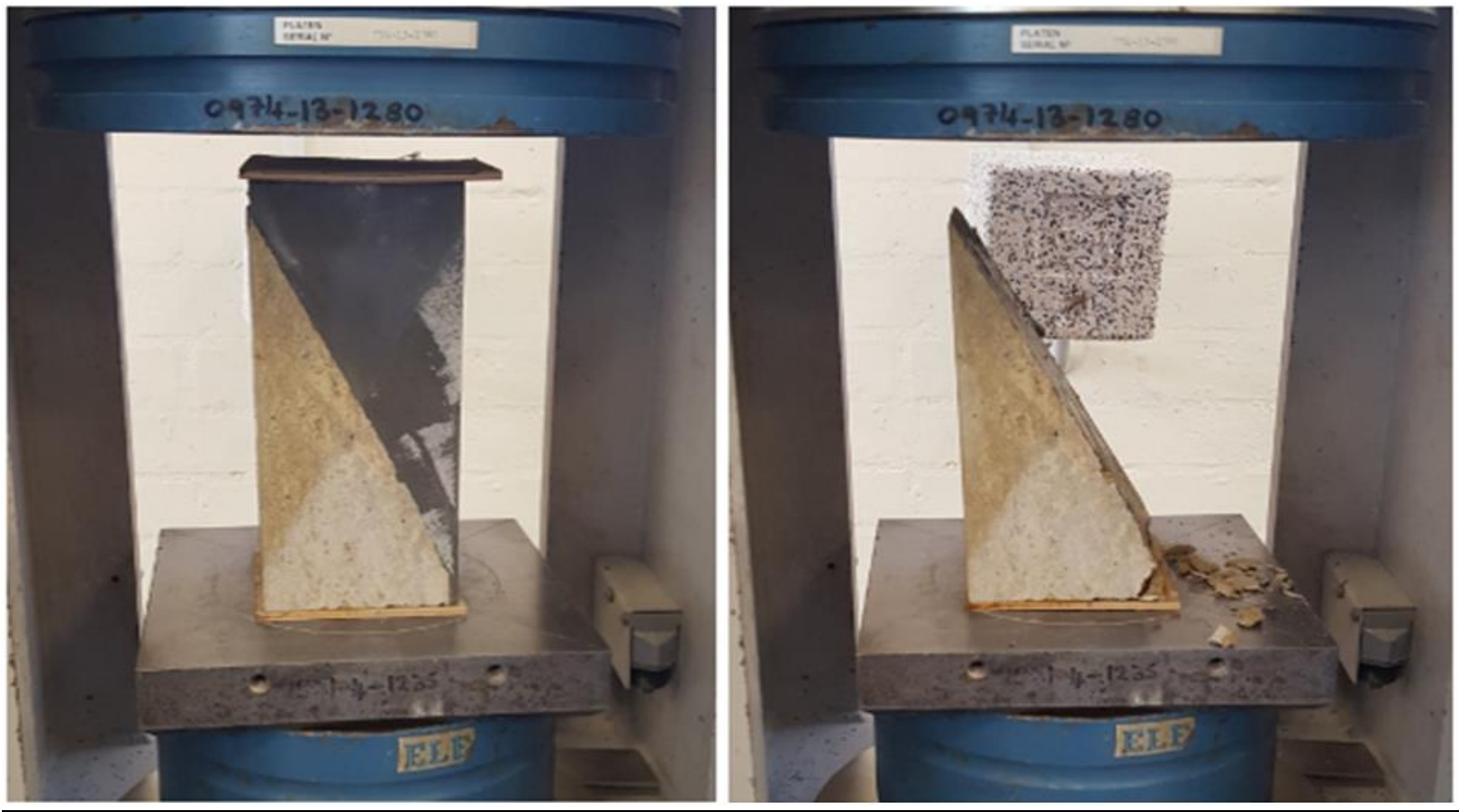

Fig. 9: Adhesive failure for specimens with $20 \mathrm{~mm}$ base height.

The simulation took place for the specimen (25/37) in set B recorded uniform distribution of shear stresses at the interface. Hence, the reason behind the adhesive failure may be attributed to the $20 \mathrm{~mm}$ base height adopted. This contradicts Santos who concluded that $100 \mathrm{~mm}$ is the minimum height for the base [7]. 


\subsection{Set 3 and Set $C$}

Regarding bond strength, $11.6 \mathrm{MPa}$ and 6.71 had been determined in the UHPC and HPC specimens, respectively. This may be attributed to the role of silica fume as in the previous sets.

Regarding the failure mode, a cohesive failure was reported in both specimens. Moreover, a broken corner was noticed in the specimens as shown in figure 10. The simulation for the model in set $\mathrm{C}$ reveals a change in shear stresses at the beginning of the interface. Therefore, the broken corner reported in set 3 of the experiment may be attributed to the change of stresses at the bottom end of the specimen.

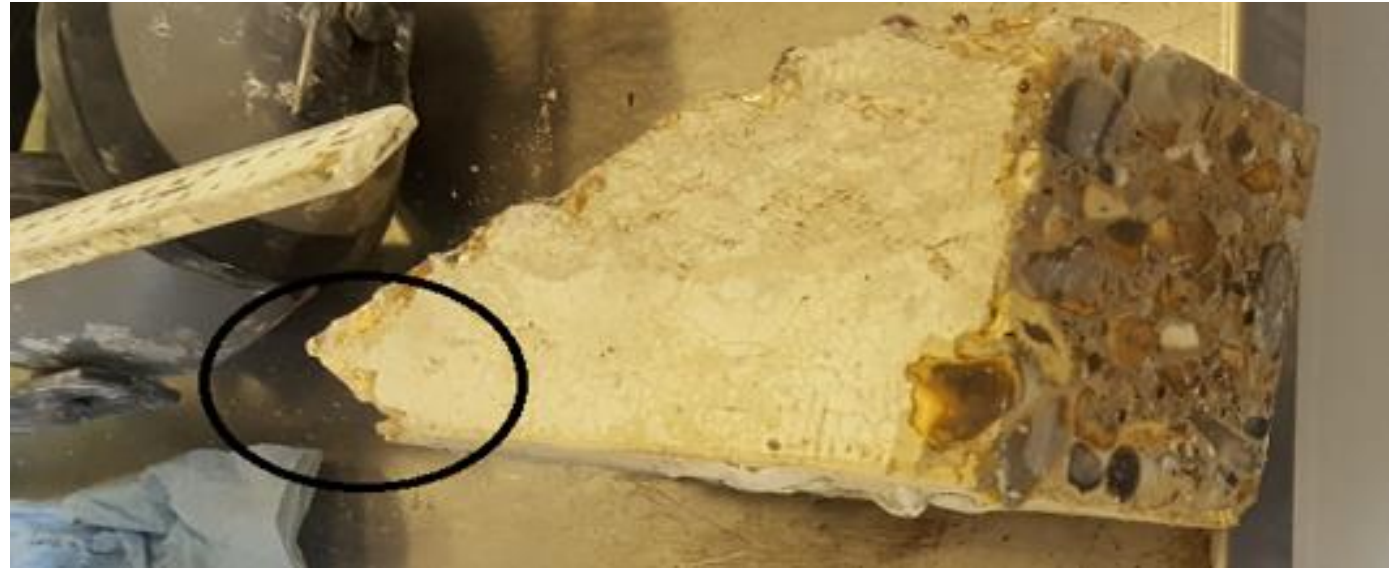

Fig. 10: Broken corner.

\section{Conclusion}

Based on this study, the following can be concluded:

- The two halves of any specimen proposed are with high differential stiffness. However, for any base height and in any set, the specimens that possessed higher silica fume in the overlay revealed higher bond strength. Therefore, silica fume has influence in the concrete-to-concrete bond strength. It can be stated that UHPC, due to the presence of silica fume, strengthens the bond strength.

- The HPC-overlaid specimens in set 1 and set 2 are of the same differential stiffness between the halves, same curing, similar overlay and substrate, exact surface roughness and equal angle of friction. However, they are of different base heights and hence different geometries. The failure mode revealed was cohesive in set 1 and adhesive in set 2 . Therefore, it can be stated that height has influence on the failure mode of slant shear specimens and it should be taken into consideration as any other aforementioned parameter.

- The experimental program for specimens possessing base height of $20 \mathrm{~mm}$ reported adhesive failure (set 2). Additionally, the numerical analysis conducted on a specimen with $20 \mathrm{~mm}$ base height (set B) recorded uniform distribution of shear stresses. Therefore, it can be stated that adhesive failure is the failure mode for slant shear specimens with $20 \mathrm{~mm}$ base height.

- The experimental program for specimens in set 3 possessing different base heights in each half reported a broken corner. The numerical analysis conducted using LUSAS on a specimen with different base height (set C) displayed a change in stress distribution at the bottom end of the interface. Therefore, it can be stated that the difference in base height between the two halves of a specimen leads to a change in stress distribution at the bottom end of the interface revealing a cohesive failure and potentially a broken corner.

\section{References}

[1] ASTM International. (2013). ASTM C882/C882M: Standard Test Method for Bond Strength of Epoxy-Resin Systems Used With Concrete By Slant Shear. West Conshohocken: Author. 
[2] British Standards Intitute. (1999). BS EN 12615: Products and systems for the protection and repair of concrete structures-Test methods- Determination of slant shear test. Retrieved from https://bsol.bsigroup.com/Bibliographic/BibliographicInfoData/000000000019970390

[3] Saldanha, R., Julio, E., Daniel, D.-d.-C., \& Santos, P. (2013). A modified slant shear test designed to enforce adhesive failure. Construction and Building Materials, 41, 673-680. doi:https://doi.org/10.1016/j.conbuildmat.2012.12.053

[4] Diab, A., Abd Elmoaty, A. E., \& Tag Eldin, M. (2017). Slant shear bond strength between self compacting concrete and old. Construction and Building Materials, 130, 73-82. Retrieved from https://doi.org/10.1016/j.conbuildmat.2016.11.023

[5] Wan, Z. (2011). INTERFACIAL SHEAR BOND STRENGTH BETWEEN OLD AND NEW CONCRETE. (Unpublished masters thesis). Louisiana State University, Louisiana. Retrieved from http://digitalcommons.1su.edu/gradschool_theses/865/

[6] Mohammadi, M., Moghtadaei, R. M., \& Samani, N. A. (2014). Influence of silica fume and metakaolin with two different types of interfacial adhesives on the bond strength of repaired concrete. Construction and Building Materials, 51, 141-150. doi:

https://doi.org/10.1016/j.conbuildmat.2013.10.048

[7] Santos, P., \& Julio, E. (2010). Assessment of the shear strength between concrete layers. 8th fib International PhD Symposium in Civil Engineering. Retrieved from https://www.researchgate.net/publication/268817145 